\title{
Intermediate cities in Latin America risk and opportunities of coherent urban development ${ }^{\text {is }}$
}

\author{
J.-C. Bolay*, A. Rabinovich \\ Laboratory of Urban Sociology/IP5-NCCR N-S and VPF-Cooperation, \\ Swiss Federal Institute of Technology, 1015 Lausanne EPFL, Switzerland
}

Urban agglomerations continue to be defined primarily by spatial and demographic criteria which signal their position within the domestic and international urban networks. We consider that these criteria are overly static, and lack indicators of both the potential inherent in medium-sized cities, and the risks they are prone to. On the occasion of a research action project conducted jointly with the Urban Management Program for Latin America and the Caribbean (PGU-ALC/HABITAT), we attempted to gain a deeper understanding of medium-sized cities in order to see more clearly what varied relations they entertain with their immediate or more distant environment. There are different aspects to the integration of an urban community in a specific context. Territorial occupation and demographic expansion, as well as urban planning and development, socio-economic, political, institutional, environmental, and cultural aspects, infrastructures and services. All these interact at different levels-local, regional, national and international. The interplay between these various aspects and their relative importance also determine intermediate cities, which act as an interface to the outside world. In doing so, they face constraints arising from ill-controlled urbanisation processes, but are also rich in possible strategies for new opportunities, exchange, and trade. Results from the local observatories set up by the PGU in four Latin American cities led us to conclude that urban players still lack an understanding of intermediate cities, and are thus incapable of effectively integrating the concept in their political development strategies. Most public, scientific or associative participants in such projects view the process of "intermediation" as a local marketing phenomenon that aims to "sell the city" in the globalised market. Economic deregulation and political decentralisation have eroded the importance of the central state and of the national territory it is meant to administer. These increasingly lose their reference value for urban players, who view their future in international terms. In contrast to the brilliant future promised to intermediate cities in the global free market, the real problems of the outside world that confront both authorities and inhabitants are completely obscured. They include such major issues as migratory movements and their impact on territorial planning and urban infrastructure, or the degradation of the urban environment, of natural resources and of the surrounding rural regions. To this day, the concept of intermediate cities is misused. In fact, it seems to cause more confusion than anything else when defining urban systems and understanding their dynamics. If it were better understood, its typological characteristics and appropriate indicators could turn it into a formidable instrument for analysing urban reality and managing the interaction between cities and their environment.

(c) 2004 Elsevier Ltd. All rights reserved.

Keywords: Intermediation; Medium cities; Intermediate cities; Urban growth; Urban management; Urban monitoring; Globalisation; Demographic changes; Governance; Participative observatories; Action research

${ }^{3}$ The present paper is based on a study conducted jointly by the UN Urban Management Program/Latin America and the Carribean (UNCHS + PNUD) with funding from the Swiss Agency for Development and Cooperation (SDC).

${ }^{*}$ Corresponding author. Tel.: +41-21-6933012; fax: +41-216936010. e-mail: jean-claude.bolay@epfl.ch

${ }^{1}$ http://nccr-ns.epfl.ch/
Is there need for a discussion of intermediate cities?

Although it is widely recognised that Third World urbanisation primarily gives rise to major metropolitan centres, it is by no means limited to this 
Table 1 Percentage of population living in urban areas and average annual rate of growth by major area

\begin{tabular}{llllll}
\hline & $\mathbf{2 0 0 0}$ & $\mathbf{2 0 1 5}$ & $\mathbf{2 0 3 0}$ & \multicolumn{2}{c}{ Urbanisation rate of growth (\%) } \\
\cline { 5 - 6 } & & & & $\mathbf{1 9 7 5 - 2 0 0 0}$ & $\mathbf{2 0 0 0 - 2 0 1 5}$ \\
\hline World & 47.0 & 53.4 & 60.3 & 2.5 & 2.0 \\
More developed regions & 76 & 79.7 & 83.5 & 0.8 & 0.4 \\
Less developed regions & 39.9 & 48.0 & 56.2 & 3.6 & 2.6 \\
Latin America and Caribbean & 75.3 & 79.9 & 83.2 & 2.7 & 1.7 \\
\hline
\end{tabular}

Sources of data: UN (2002), UNCHS (2001).

upper scale of the urban hierarchy. The ills that affect the metropolis - density of the population and of the built environment, segregation and social violence, economic exploitation and poverty, precarious settlements and pollution-motivated us to examine smaller cities in the urban network for their strengths and weaknesses with regard to urban management and the environment-in a word, with regard to sustainable development. Often called medium-sized cities because of their population and built surface area, they are also intermediate cities whose existence and dynamics depend directly on trade and other forms of exchange, whether near or remote, in which they participate.

More than just a quibble about terms, the interest of such a reflection lies in that it is likely to generate a better understanding of the specificities of intermediate cities, and of their position relative to demographic, economic and political exchange in developing countries. It arises from a scientific and operational will to make urban promotion strategies more appropriate to the specific agglomeration they target. As medium-sized cities that are well integrated within a rural region, they are - unlike the great metropolitan centres - seen as playing a crucial role in rural-urban interactions given the usually strong link and complementary relationship with their rural hinterland (Baker and Claeson, 1990 in Tacoli, 1998). They offer rural populations better living conditions, jobs, a less polluted environment, and act as local markets for their products. They also provide services and a collective infrastructure, not only to the urban but also to the rural and regional population. In some regions, generally within more industrialised areas or close to large cities, many smaller urban centres have succeeded in attracting new investments that previously would have tended to concentrate in large cities (Tacoli, 1998). On the other hand, these cities face a certain number of obstacles they must deal with if they wish to strengthen their position. They must be made more attractive for investors, more competent in their municipal administration, more stable thanks to sound financial management. In spite of these considerations, the overwhelming importance of metropolisation, which raises questions on a massive scale, and is characterised by problems that affect several million people, causes medium-sized cities to be studied too rarely (Bolay, 1995; Pedrazzini, 1995).

For the past 50 years, our world has been going through a phase of urbanisation that is still picking up speed. Its most visible signs are complex and conflict-ridden management, hard put to cope with the immensity of problems it faces, inadequate resources, and power struggles to control wealth (Paquot, 1996). Statistics confirm that metropolisation continues to be a major trend. But there are many other transitory situations, and many cities with a smaller population are remarkably active at local and regional level, playing an important part in the economic and social evolution of developing countries. $^{2}$

According to the United Nations (UNCHS, 2001 ), in the year 2000, the world population was 6.05 billion, of which $47 \%$ lived in an urban environment $(76 \%$ in the Western industrialised countries, as against only $39.9 \%$ for the totality of developing countries). This rise is bound to continue, reaching $53.4 \%$ in 2015 for the planet as a whole (see Table 1). However, the most important aspect of this accelerated urbanisation process is that it is by no means uniform. It differs depending on world region and type of city. All in all, one can say that urban growth affects primarily the developing world $(3.6 \%$ annual growth rate between 1975 and 2000 against 2.5 worldwide).

Moreover, this trend is marked by polarisation which concentrates an ever larger number of citizens within enormous metropolitan areas (territories of over 1 million inhabitants that generally extend beyond their administrative municipal boundaries). Thus, the number of metropolitan centres was estimated to go from 83 in 1950 to 325

\footnotetext{
${ }^{2}$ Although figures vary strongly from one region to the next, Latin America offers a fair illustration of the distribution of the urban population according to type of city or town: in Spanishspeaking South America, there are about 20 cities with a population of $300,000-500,000$, about 10 with 500,000 to a million inhabitants, 15 with population of 1-5 million, three with 5-10 million inhabitants, and one (Buenos Aires) of over 10 million. In Portuguese-speaking Brazil, there are about 15 cities of approximately 300,000 inhabitants, 14 with more than 1 million, and two mega-cities of over 10 million, Rio (10.8 million) and Sao Paulo (18.3 million). In Central America and the Caribbean, one finds about 20 cities of over 500,000 inhabitants, about 15 of over 1 million, and six of more than 5 million. Mexico City has a population of 18.3 million (Colin-Delavaud, 1994; UN, 2002).
} 
Intermediate cities in Latin America: $J$-C Bolay, A Rabinovich

Table 2 Distribution of the urban population of the world by size of urban settlement in 2000

\begin{tabular}{llllrl}
\hline & $\mathbf{1 0}$ million or more & $\mathbf{5 - 1 0}$ million & $\mathbf{1 - 5}$ million & $\mathbf{5 0 0 , 0 0 0 - 1}$ million & Less than 500,000 \\
\hline World & 7.9 & 5.9 & 23.6 & 10.1 & 52.5 \\
More developed regions & 7.5 & 4.4 & 24.1 & 8.6 & 55.4 \\
Less developed regions & 8.0 & 6.6 & 23.3 & 10.8 & 51.2 \\
Least developed regions & 7.3 & 3.0 & 22.6 & 8.4 & 58.8 \\
Latin America and Caribbean & 15.0 & 5.0 & 21.9 & 10.0 & 48.1
\end{tabular}

Source of data: UN (2002).

in 1995 , with a majority in developing countries (Ayuntamiento de Lleida, UNESCO, UIA, 1999). However, this trend should not make us forget that a majority of the urban population still lives in smaller agglomerations. Worldwide, it is estimated that $54 \%$ of city dwellers live in centres of less than 500,000 inhabitants. In Latin America, where 95\% of municipalities have a population of less than 100,000 , the proportion of the urban population living in cities of less than 500,000 is of 48.1. In both the more and the less developed regions, the majority of the urban population lives in urban centres of approximately 500,000 inhabitants ${ }^{3}$ (see Table 2), and will continue to do so. Thus, metropolisation is a real process in that concentration in the largest agglomerations continues. But we overlook somewhat hastily that the other strata of the urban network also host a large population, and that their proportion has a tendency to grow to the detriment of very small settlements which stagnate due to lack of opportunity, and of multimillion agglomerations with a statistically slower growth rate.

This trend is also highly symptomatic of economic and technological change in a world that is no longer developing, but truly becoming globalised-or even "metapolising". 4 The depth and consequences of these changes tend to overshadow the situation of other agglomerations. Nonetheless, the globalisation of economic exchange and trade which does away with protective trade barriers for the poorest countries, the free market it intends to impose worldwide, and political and administrative decentralisation which is being introduced in most developing countries (Rossi et al., 1999) repositions cities that used to be perceived as provincial and sleepy as credible national or international partners or even competitors. Obviously, this calls for an attempt to perceive their role in the urban network, and their present and future field of action. The notion of "intermediation" should facilitate this

\footnotetext{
${ }^{3}$ Medium cities and towns have absorbed in the past and are expected to continue to absorb in the future the largest share of the annual increment of the world's urban population: $50 \%$ during 1975-2000 and 44\% during 2000-2015 (UN, 2002).

${ }^{4}$ According to the terminology of Ascher $(1995,2000)$, metapoles are new urban centres consisting of at least several hundred thousand inhabitants. They may have regional scope; they may be discontinuous, heterogeneous, polynuclear, little by little integrating ever more distant towns and villages.
}

task by enabling us to distinguish between internal constraints linked to the political and social context, and the potential impact of an opening that these cities are aiming for.

It might prove useful, in this sense, to examine whether the "intermediation" process that catapults them into the outside world represents an opportunity or a risk. However, the terms of the problem must be stated clearly first, and this is rarely done. The relevant literature (Galileo, 1994; Hardoy and Satterthwaite, 1989; Petrella, 1996; Ayuntamiento de Lleida, UNESCO, UIA, 1999) often makes use of confused terminology, incongruously applied.

In essence, it would be more interesting to pass from a "topological" view of an agglomeration's demographic and spatial characteristics - a static image reflecting a given status quo- to a more dynamic vision based on the functions that any urban community undertakes while interacting with its environment. In this sense, "intermediation" expresses the concerted and voluntary, or involuntary, forms of exchange that a community, identifiable in social and spatial terms, develops at various levels for the dimensions that directly or indirectly circumscribe life in society: work, population movements, the environmental impact of human activity, social and cultural relations, etc.

It is quite likely - and this may be stating the obvious - that we shall rediscover that every city, whatever its population and size, is to some extent an intermediate city. Its survival and development forcibly depend on the relations-from fruitful cooperation to violent conflict-it establishes with external partners of all types. We clearly cannot limit ourselves to general observations of this kind, but will attempt to link up criteria identifying urban centres (population, territorial size) and traits that structure their existence (geographic location, morphology and available natural resources, modes of management, social and institutional specificities, the economic fabric, etc.) with the elements that place them squarely within a world that by far surpasses their physical or administrative boundaries. The interplay between its internal characteristics, on the one hand, and the risks and opportunities of an opening on the other, should enable urban players to rethink their activities more in line with contemporary reality. This must include an awareness of the opportunities offered 


\section{Intermediate cities in Latin America: J-C Bolay, A Rabinovich}

by globalisation, but also of the terrible competition it generates, and a full appreciation of the impact that an excursion into the great wide world may have on urban management.

These issues require a global analysis leading to specific recommendations apt to facilitate the work of urban development players: public or private administrators, local or regional decision-makers, persons in charge of international development cooperation programs.

\section{"Intermediation": between concept and operational tool}

"Finally, the medium-sized city is defined more by the position it occupies and the role it plays not only in the urban network but also in the global economic system, quite pertinently overlapping with the term of intermediate city. The latter is primarily determined by its position between local centres with direct contact to the rural world, or specialised towns ${ }^{5}$ on the one hand, and metropolitan centres that function at national and international level on the other" (GRAL/CEDAL, 1994: p 130). Thus, intermediation is synonymous with action, exchange and an opening towards the outside; while the many contexts in which the city fulfils its intermediate function imply that the diverse dimensions accounted for when analysing it as a phenomenon are added to the various overlapping and interlinked levels at which cities relate (Bolay et al., 2002: p 70). Thus, with reference to the metapole concept, for example, Ascher reminds us that many intermediate cities find it difficult to " position" themselves between the metapoles on the one hand, and small towns and rural areas on the other hand. ${ }^{6}$

These statements point directly to the queries that will guide our definition of the concept of the "intermediate city": What aspects should be accounted for? At what level do these aspects set in? And of course: who are the players behind these changes? As a first step, we must pass from a bi-dimensional definition of the medium-sized city (surface size and population ${ }^{7}$ ) to a multi-dimen-

\footnotetext{
${ }^{5}$ As can be tourist spots, border cities with "maquiladoras" or high-tech industrialised cities.

${ }^{6}$ The rise of metapoles puts into doubt urban hierarchies and the theories on urban structure that have been extensively described and analysed by geographers and economists. In a "metapolitan" system, only major cities are linked directly to many other agglomerations, whereas smaller towns have a direct link to only one major city. This amounts to the rise of a metropole-centred urban system functioning within an international network that makes the older system in which influence and relations determine the hierarchy of towns and cities less pertinent (Ascher, 1995).

${ }^{7}$ Demographic aspects, which vary according to region or country, allow us to establish a "critical size" that marks the threshold at which the organisation of the urban territory and of the society that makes it live grows more complex, and thus necessarily more dependent on outside relations.
}

sional and multi-scale approach that will also focus on the economy, the environment, urban planning and development, public infrastructure and services, political and institutional structures, and social and cultural aspects. The territorial location of the intermediate city will determine its function within its region, and the role it will play at different territorial levels, alongside the other agglomerations of the urban network. This should provide us with a multi-faceted yet characteristic view of how urban players manage and promote their city and its interests. Depending on their location, spatial integration, social and economic structures and relations with other cities, but also on the particular characteristics of the urbanisation process in each country or region, intermediate cities reflect very diverse local or regional situations. Our study of four intermediate Latin American cities (PGU/ $\mathrm{ALC}^{8,9}$ enabled us to identify 11 major "formal" types. These types do not aim to provide an exhaustive overview of intermediation; they recapitulate the main elements, which may differ according to situation and country, that constitute exchange between the city and the rest of the world, be it near or far. Some may be mutually incompatible, although in most cases they are either complementary or overlap (Table 3).

To interpret this typology, it has proven useful to define how cities act towards the outside world, firstly in term of main aspects characterising intermediation (multi-dimensional analysis). We defined eight fundamental dimensions: ${ }^{10}$

- Demographic, based on urban growth and the impact of migratory movements

- Economic, based on identifying the productive and trade sectors that feed the local and external goods and services markets

- Political and institutional, based on analyses of public institutions serving the local population, in line with their nature, function and territorial scope

- Services and equipment which are specialised and sophisticated enough to offer services to both the endogeneous and the exogeneous population

- Environmental, by identifying natural and built resources that facilitate collective life and by-on

\footnotetext{
${ }^{8}$ For a description of dimensions, variables and indicators see Bolay et al. (2002).

${ }^{9}$ The Urban Management Program (General Secretariat for Latin America and the Caribbean) has joined forces with the Institute of Research on the Built Environment (IREC, now the Urban Sociology Laboratory, LaSUR) at the Lausanne Federal Institute of Technology (EPFL), with funding from the Swiss Agency for Development and Cooperation (SDC) (Bolay et al., 2002).

${ }^{10}$ For a detailed description of these dimensions of "intermédiation" and of the variables, see Bolay et al. (2002).
} 
Table 3 Typology of urban functions

\begin{tabular}{|c|c|c|}
\hline 1. & Regional market & $\begin{array}{l}\text { The city is a driving force for the production and exchange of goods } \\
\text { and services at the level of the local and immediate regional economy }\end{array}$ \\
\hline 2 & Service centre & $\begin{array}{l}\text { The city offers a number of public services - health care, secondary and } \\
\text { tertiary educational institutions - as well as private services-banks, } \\
\text { businesses, leisureand information centres - for both the urban community } \\
\text { and the surrounding population }\end{array}$ \\
\hline 3 & Regional capital & $\begin{array}{l}\text { The city hosts various provincial and/or national political and administrative } \\
\text { institutions for the territory in which it lies }\end{array}$ \\
\hline 4 & Economic location & $\begin{array}{l}\text { The city develops a concerted national and international strategy as a large-scale } \\
\text { industrial and trade centre, by making the necessary infrastructural investments and } \\
\text { facilitating the action of economic agents }\end{array}$ \\
\hline 5. & Tourist centre & $\begin{array}{l}\text { The city makes use of its comparative advantages-location, natural resources, } \\
\text { historic legacy, culture, etc.-- to promote activities linked directly to domestic } \\
\text { and/or international tourism }\end{array}$ \\
\hline 6. & Communication hub & $\begin{array}{l}\text { Owing to its strategic location and the development of relevant infrastructure, } \\
\text { the city acts as a platform for the exchange of persons, goods and information }\end{array}$ \\
\hline 7. & Metropolitan periphery & $\begin{array}{l}\text { The growth and development of the city depend directly on its integration within } \\
\text { a metropolitan area with its underlying national and international dynamics }\end{array}$ \\
\hline 8. & $\begin{array}{l}\text { National/international } \\
\text { interface }\end{array}$ & $\begin{array}{l}\text { The city's geographic location (border zone, coast, city-state) and its development } \\
\text { strategy (duty free zone, "maquiladoras", international tourism) endow it with a } \\
\text { role shaped primarily by ever more international exchange mechanisms }\end{array}$ \\
\hline 9. & Cities in a conurban area & $\begin{array}{l}\text { The city's development depends on its integration within an agglomeration } \\
\text { of several urban municipalities linked together at various levels of the urban } \\
\text { framework, with each municipality retaining its own identity }\end{array}$ \\
\hline 10. & $\begin{array}{l}\text { Association of a group } \\
\text { of towns }\end{array}$ & $\begin{array}{l}\text { Several small towns in a preponderantly rural region constitute a group and } \\
\text { influence each other }\end{array}$ \\
\hline 11. & Urban region & Settled areas within diffuse urban zones \\
\hline
\end{tabular}

the other hand-stigmatising the depth and extent of contamination by urban activities

- Territorial management, focusing primarily on planning and organising the built environment and its consequences on human settlements and its populations

- Social, reflecting behavioural changes and mingling within family and social networks

- Cultural, via the appearance of new forms of expression synthesising local cultures and outside influences arising from exchange between urban populations and their external contacts (linked directly or through the media)

Second, to complete the typological analysis we identified a three point scale for intermediate cities (multi-scale analysis). Combinations of the above criteria will prompt the city to interact in "a variable spatial geometry", involving both the immediate suburban and rural periphery, and more distant regions that have gained a measure of virtual proximity thanks to the new communication and transport technologies.

We identified:

- The local and regional scale, in which the relations between a city and its direct environment are established, both urban-rural (hinterland) and within micro-networks of towns of different size and function:
- At the social level, through the complex ties between rural and urban individuals and families.

- At the economic level, as an agricultural production and sales centre, with small industries and services linking the rural and the urban economy.

- At territorial and infrastructural level, as a spatial unit organised by a given society in order to make the best use of available land and deploy the most promising social and economic activities.

- At political and institutional level, as an urban and regional decision-making sphere for all basic human activities that define life in society.

- The national scale, settling all issues that link the city and its players to the national territory:

- Through its more or less harmonious integration within the urban networks, contacts established with other regions in the country, and with the interdependence between local society and the various supervisory bodies set up by the central state or provincial authorities

- The international scale, dealing with the relations that link a city and its supra-national and worldwide environment:

- Organised in autonomous and proactive manner by the city and its players 
- Within the framework of an overriding strategy elaborated by the national authorities or supervisory bodies

- Via an international role specified directly by the tenets of trade globalisation which benefit or otherwise affect the city's present and future position.

Such an investigative structure establishes rational and understandable lines for an intermediate city's development, accounting for its various aspects and scope by focusing on what characterises it internally, and on its relationship with the outside world. The avowed aim of such an approach is the optimal management of a settled space with which its inhabitants identify. The path to follow should no longer rely exclusively on local, voluntarist and projective approaches, which often prove sterile since they are not well-founded enough. It should include active planning based on a balanced evaluation of the pros and cons of outside exchange. It is better to know and understand these mechanisms and guide them, than merely "imagine" them and possibly suffer their subsequent negative effects.

The establishment of local observatories in four cities representing one of the intermediate city types enabled us to confront our conceptual and methodological premises with an extremely heterogeneous reality. It also allowed us to avoid analytic confusion, inexact information, and ideological rather than rational decisions due to this diversity.

The projects launched in Maranguape (Brazil), Camilo Aldao (Argentina), Manta and Cuenca (Ecuador) have led us to believe that such an approach is not only possible, but that it offers an instrument fostering democratic governance between the local players. It may also serve as the basis for a more in-depth reflection on the principal options open to public and social decisionmakers with regard to the future of their city or region.

\section{Applications for Latin America: an analysis of four intermediate cities}

The four cities were selected on the grounds of the criteria presented above, and of practical considerations: cooperation between the city in question and the UNDP-UNCHS Urban Management Program, previously existing cooperation between municipal authorities and civil society representatives, strong motivation to take part in a research project. This led to the choice of four cities apt to serve as sites of urban observatories analysing the "intermediation" process.

Each shows some major traits listed in our typology. This "urban personality", the outcome of each city's local and regional history, has proved important in the choice of priorities and aspects examined by the study.

Camilo Aldao is a small town (population approximately 5000) which lies in the centre of the agricultural Argentine pampa. It serves as both a service and market centre for a rural region with modern and extensive agricultural production. It has also administrative and political functions in the Marcos Juarez department, which makes it a driving force behind an association of 21 municipalities in this and the neighbouring department, with 50,000 inhabitants. Its functions are primarily economic, in second line political and administrative.

Maranguape's situation is opposite to that of Camilo Aldao. It is quite a large agglomeration, with a population of almost 90,000, of which 50,000 live in the capital, and the remaining in a network of 15 small agglomerations. It lies in the direct sphere of influence of Fortaleza, the metropolis of the Nordeste, and the fifth city in Brazil with a population of over 2 million. Located at a distance of $24 \mathrm{~km}$ from Fortaleza, Maranguape is a periphery dominated by a metropolitan centre, in economic, migratory and residential terms.

Maranguape nevertheless has its own local political area of influence, since it is the capital of an administrative district. In this metropolitan configuration, it seconds Fortaleza, and offers a number of services to the urban and neighbouring rural population. It also functions as a communication hub for public transport that is based in Fortaleza and services the state of Ceará. Moreover, owing to international and domestic competition, the entire metropolitan area presents a low-cost alternative for a number of internationally active businesses.

Cuenca, with a municipal population of about 300,000 , three-quarters of which are urbanised, can hardly be considered a medium-sized city by the territorial and demographic standards of Ecuador. It is the third agglomeration in the country after Guayaquil and Quito. However, as the capital of Azuay province, it perfectly corresponds to the criteria defining an intermediate city, in that it serves as a service centre for this region of southeastern Ecuador, and is an important market centre.

The economic crisis increases its dependency at international level. Domestic economic stagnation has caused a massive exodus of the working population to the USA and Europe. It is estimated that $30-40 \%$ of the money sent by expatriates are reinvested in the Cuenca region. This severely distorts the real estate, land and consumer goods market. In just a few years, Cuenca has become the most expensive city in the country.

Manta, on the other hand, is a city that looks outward. A port with a population of almost 200,000 , it is the second largest maritime centre of 
Ecuador, after Guayaquil. This intermediate city thus has to be judged primarily in terms of international transactions, as an economic hub acting as an interface that links a fishing industry of great domestic importance with an international distribution and consumer network. This development strategy targeting international markets is seconded by the authorities' plans to attract foreign tourists.

However, these world scale projections should not make us forget that, for the time being, the port has a direct impact on the Manta metropolitan zone. This consists of the city and five neighbouring municipalities, and serves as both regional market and service centre, in terms of public infrastructure and of a number of activities that are difficult to control - the informal economy, or new settlements, for example.

\section{Monitoring: the path towards local operational governance}

In order to track the process of urban intermediation in each of the four designated cities so as to pinpoint the types of interaction generated both locally and globally, we had to set up a data production, monitoring and control tool. This in turn prompted the regional coordination of the Urban Management Program (UMP) for Latin America to propose the set up of local observatories, an experiment, which proved highly effective for data collection and analysis. It also makes it possible to reorganise urban management in each agglomeration with a view to introducing forms of local administrative and technical governance that are more apt to integrate the urban stakeholders who play a decisive role now, or will do so in the future.

Invariably, a discussion of monitoring intermediation at various levels in Latin American cities brings us to reposition it conceptually within the extensive debate on the notion of governancewhich in our case is urban and local. We have two ways of approaching this issue, the first being more directly managerial, the second more theoretical and critical. Let us first consider the second approach.

Stren (2002) discusses the fact that the notion of governance, as popularised since the 1990s, repeats the essential points of the definition proposed as of 1997 by the UNDP: "The exercise of political, economic and administrative authority in the management of a country's affairs at all levels. Governance comprises the complex mechanisms, processes, and institutions through which citizens and groups articulate their interests, mediate their differences, and exercise their legal rights and obligations". Every element of this definition is important: first, it stresses the complexity of decision-making mechanisms. Second, it insists upon the fact that the issues discussed are multi- dimensional, involving not only the political and administrative sectors, but also the economy and its social impact, as well as various specific interest groups and how they relate. In our urban research projects, this analytic framework provided by governance allows us to answer two key questions for the development of these cities: what rules guide decision-making processes? who are the players involved, what are the context and constraints within which they operate, their source of power or authority, and how do they relate to each other? (Rakodi, 1999, citing Devas, 1999).

Two comments may be useful to stake out a theoretical framework within which to interpret innovative initiatives for the urban environment. According to Merrien (1997), the notion of governance enables us to "stress the evolution of public action: a relative fall-off in state capacity for action, a crisis of legitimacy of the public sphere, intervention at all levels of public action by private sector agents and institutions, the new-found importance of the market paradigm..." Moreover, this crisis of the state and of its recognition as a driving power for change goes hand in hand with a redefinition of the representative civil society stakeholders. This transition from a vertical administration (the central state which issues orders to the lower echelons which implement them) towards more horizontal forms of management sees the rise of interest groups that have long been acknowledged partners of public action (private companies, associations and NGOs, trade unions, churches, etc.). These organisations that now participate in and inspire governance, are accompanied by structures that organise the "informal sector", particularly in the developing countries (UNESCAP, 2003); they go from socially legitimate groups of the population to clientelist or mafia-like networks that poison public life.

That said, and in view of the insistence on good governance underlined by Peemans (2003) (in the terminology used by the international organisations), we must reposition this issue within its ideological context, which is marked by the triumph of democracy via the market economy; the latter weakens the role of the state while imposing a number of regulations aiming for structural readjustment: administrative and political decentralisation, a strengthening of the private sector, the abolition of customs barriers. At the level of cities which are the subject of our research, this means, over and above decentralisation, new forms of participatory management and more democratic political processes, and adapting to the new political and economic conditions that come with globalisation.

The considerations concerning the ideological bases of societal changes should not lead us to reject the new dynamics that the latter might bring in the area of urban management and the resulting 
interactions between cities and their environment... Pugh (2000) reminded us in this context that "governance is not simply intangible and immaterial: it can be used in policy, planning and economic production" by means of a multiplayer organisation, bottom-up awareness of problems and their priorities, and by reinforcing the individual and institutional competencies of the urban partners involved. Also, one should not forget that to ensure their social impact these strategies should focus on the most disadvantaged social groups and defend their civic rights (Healey and Robinson, 1992).

Good urban governance consists of a synthesis of characteristics linked to each of the following denominators: governance is a process built on complex relations between players; within this process, conflicting and diverse interests may be expressed in a joint perspective that links institutions and social organisations (HABITAT, 2003). This governance will be "good" when it leads to inclusive and well-managed proposals. In the rural environment, good governance will tend to promote the well-being of all citizens by respecting their civic rights and access to the necessities of urban life, including adequate shelter, security of tenure, safe water, sanitation, a clean environment, health, education and nutrition, employment, and public safety and mobility.

These elements preside over the set up of the urban observatories established in each of the four agglomerations examined in the project. These bring together various organisations and institutions of urban society and were created in order to collectively gather the data required to monitor and analyse intermediation (Bolay et al., 2002). This "socialisation" of the action research process commits the partners for the future via their participation in a joint project which goes beyond the strict limits of building and aims to capitalise the results obtained by the reformed management of urban spaces and the people who transform them.

Our study, which is the result of a collective partnership, offers valuable information on pressing urban issues. Unlike the tendency for urban studies to focus on how to market cities, scientific analysis imposes a certain rigour when assessing the potentials of, and obstacles to, urban development. The latter approach categorically implies the direct involvement in the research of all urban stakeholders: public administrations and their officials, representatives of civil society, and local scientists. This ideal vision has not always been successfully applied in case studies; combining serious scientific work with the operatives' enthusiasm is feasible only in long-term projects. Consequently, local intermediation observatories were set up, promoting governance and contributing to the renewal of urban management.

\section{Demographic change: omnipresent but obscure}

As said formerly, urbanisation in the developing countries is first of all a movement at the crossroads between demographic pressure and available land. This equation is rarely simple for those who manage the urban space. Indeed, it generates a host of severe development-related problems: the uncontrolled expansion of urban zones, precarious settlements, inadequate infrastructure, the deterioration of natural resources, to name just these (Hall and Pfeiffer, 2000; Marcuse and Van Kempen, 2000). Our evaluation of urban demographic growth distinguishes between natural growth and immigration, although we are fully aware that at a primary stage of urbanisation, population movements tend to be a more significant demographic factor than the birth rate. When a country or region reaches an advanced stage of urbanisation, urban growth slows down. What growth there is, is primarily generated by the city's internal dynamics. The Latin American situation is characteristic of this.

A second trend is gaining in importance: periurbanisation. The largest metropolitan centres reach their territorial and administrative limits, and land is settled and developed beyond these. Migrants also move to smaller urban centres, since they consider that their opportunities there, what with decentralisation and regionalisation, will be just as good. "In many cities, an increasing proportion of the population lives in peri-urban areas still officially designated as rural, though they consist, in fact, of new housing spilling over the official urban boundary. Many of the rural-urban flows of people, goods and waste are most intense and varied between built-up areas of towns and cities and the peri-urban areas that surround them" (Tacoli, 1998: $p$ 159). International statistics document that alongside the general metropolisation trend, cities of 100,000-1,000,000 inhabitants are becoming secondary centres of more rapid demographic growth.

Maranguape saw its population grow very rapidly from the $1970 \mathrm{~s}$. Its municipal population, which at the time was up to $60 \%$ rural, grew to 87,538 in 2000 , urbanised to $75 \%$. The first reason for this is the growing scarcity of labour in other parts of the country, which recently attracted several industries to Maranguape. Better roads and transportation have made the city more competitive against Fortaleza. Manta in Ecuador has long shown similar continuous demographic growth. Between 1950 and 2000, the population almost doubled and now reaches 177,314 . Ninety percent live within the municipal boundaries, in strongly urbanised zones. This strong growth rate $(4.7 \%$ in the 1960 s, and over $5 \%$ in the 1970 s and 1980 s) is certainly linked to the extension of port activities. It has since fallen, and now lies at about $2 \%$ annually. Besides the population explosion, the city has 
for a long time suffered from nonexistent or inadequate urban planning. A significant step was taken in 1997 with the passing of a strategic municipal urban development plan, but the "laissez-faire" attitude adopted by the urban authorities for decades caused uncontrolled expansion of many informal, precarious and unsanitary settlement zones. The new plan aims to cope more effectively with these problems.

In Cuenca, also in Ecuador, the demographic trend is strongly upset by the recent economic crisis. Although the last decades saw marked population growth, there is now a massive exodus abroad, motivated by the quest for better working conditions. Local statistical sources, though haphazard, confirm this. In 1950, the population of Cuenca was 40,000 , one-fifth of what it is today. In 1990 , it had 194,981 urbanised residents, $60 \%$ of the municipal population. Growth was strongest between 1960 and $1980(3.4 \%$ and then 3.0\% annually). The rural settlements next to Cuenca, on the other hand, have for a long time shown weak or even extremely weak demographic growth. In consequence, urbanisation is slowing down and one may assume that there is a massive exodus abroad, from both rural and urban areas. Being aware of this, the authorities try to evaluate the consequences. The risk that emigration will compromise development projects for Cuenca and the surrounding region is considerable.

As a small regional centre with access to scant demographic data, Camilo Aldao in Argentina has to be examined in more differentiated fashion. We know that it has a population of 5016 and that it lies in a rural region of 21 municipalities with a total population of 50,000 . There are no indications concerning development over time, and a diachronic analysis would have to be purely speculative. There are nonetheless quite a few initiatives aiming to counteract the exodus of the young in their search for decent education or job opportunities. It is more than likely that such initiatives are motivated by population and job loss, and that the demography is stagnating or even falling. This would be characteristic of a region with mechanised, high-tech agriculture and migration towards more attractive urban centres.

Demographic growth is real in all the cities we studied, with the single exception of Camilo Aldao. As for the other agglomerations, and in spite of recent economic upheaval, the trend is towards marked and continuous population growth over the past 30 years. Sometimes, state policies influence a city's growing importance as a destination for rural-urban migration (Tacoli, 1998). In other cases, it may be associated with a renewed emphasis on export agriculture, with the secondary cities within or close to the exporting region benefiting more than major cities (UNCHS, 1996). But generally, the impact of migrations, which are a major phenomenon in most major or medium-sized agglomerations in the developing countries, is still not very well known. This is certainly true of the four cities we studied; more than likely, it applies to intermediate cities in general. There is a definite lack of statistics. Pinpointing the origin of populations that have recently moved to an urban environment is difficult; population curves over several years can be drawn only partially, and we know nothing about the impact of migration on territorial occupation and development. This lack of precision and data illustrates how little attention is paid to a phenomenon that - all urban specialists agree - is a key factor in understanding contemporary developments. No operational link is made between population growth, impoverishment, and growing marginality for the greatest number. However, we may voice the hypothesis that the growth of medium-sized intermediate cities is fuelled by two sources: the traditional one, in which a rural population settles in the regional capital in order to gain access to modern services and infrastructure, as well as to gainful employment; and through intra-urban flows which are characterised by the movement of metropolitan populations towards smaller agglomerations offering a better quality of life and a healthier environment, or with the new residents coming from even smaller agglomerations that offer little by way of economic opportunities and services. The reasons behind these complementary phenomena are diverse, although at this level of urban stratification, they refer to what Hardoy et al. (2001) call the rural-urban linkages which can be positive in both developmental and environmental terms: an urban economy that boosts rural production and more equitable distribution of natural resources and energy - in other words more integrated regional planning in response to the unavoidable connections between urban and rural regions.

Neither political authorities nor those technically in charge of urban management seem to have integrated this situation into their planning and territorial organisation. This leads to severe social conflict in terms of the allocation of land and access to services, and political conflicts in terms of the coordination of public policies with other municipal and regional authorities. It also causes the introduction, distribution and maintenance of public infrastructure and services to be dysfunctional.

\section{Producing, transmitting and consuming: economic exchange as the basis of "intermediation"}

The economy is a primary factor in the development of Third World intermediate cities. We may observe three parallel levels of "intermediation". The link between the city and its surrounding region is established locally. As is often the case 


\section{Intermediate cities in Latin America: $J$-C Bolay, A Rabinovich}

with small or medium-sized cities, it ties them to the rural regions that supply them with food and labour. For larger agglomerations, this local link concerns peri-urban zones, i.e. a mix of settled areas, wastelands and agricultural zones. All the cities we studied are characterised by intense economic exchange at micro-regional level. Manta is the central municipality of a metropolitan zone with five other municipalities. Camilo Aldao is the regional centre of a vast agricultural region. Cuenca is a service and small-scale production centre, and capital of a rural province. As for Maranguape, as the secondary centre in the Fortaleza metropolitan region, it relies heavily on local trade with the residents and the neighbouring rural populations. It also serves as a centre for the processing of agricultural products from Ceará province, which are then consumed throughout the Fortaleza metropolitan area.

The four studies further examined the opening at national level, the second level of economic "intermediation". It is characteristic that small-scale industrial and commercial companies continue to view the domestic market as their greatest opportunity to expand. In certain countries, customs regulations put a damper on foreign competition; in others, legal and administrative know-how favours domestic businesses. Moreover, local consumer expectations and the goods and services offered by domestic producers tend to correspond, although the opening up of international markets and the abolition of numerous customs barriers may now modify this situation to a certain extent. It is still a cultural and economic reality that must be kept in mind.

But the position of the four cities in the domestic market is not very well documented. It would seem that this "intermediation" level is not at the heart of the current debate, caught between local identity (and the management of the administrative territory) and the globalisation outlook (which automatically focuses on the international scale). The economic restructuring that has shaken Brazil doubtless corresponds to its expansion onto the international markets. Yet this gives rise to domestic developments that for some time already have been favouring the Nordeste, e.g. the relocation of companies from the south to northern regions in which production is cheaper. Textile and shoe factories have notably been built in the Fortaleza metropolitan zone, in which Maranguape lies. For Camilo Aldao and the whole agricultural region of the Marco Juarez Department, the domestic market is also of primary importance. Located at the centre of the country's major grain-growing region (grain and oleaginous crops), it supplies local, national and international markets. Domestic economic flows are less important for the two Ecuadorian cities, Manta et Cuenca.
However, it would seem that local players tend to analyse present-day dynamics and make projections for the future, above all in terms of the increasingly international character of economic relations. All the cities we studied are in some way involved in international trade. In Camilo Aldao, prices of pesticides and other products required by farmers, as well as the prices of the products they market are influenced directly by international prices. The town's principal aim is to enter foreign markets, with MERCOSUR seen as a priority. The situation in Manta is even more explicit. Its maritime activity is currently generating a number of companies that export derived products. The leaders of this extensive conglomerate see expansion in international terms, so that they may become more competitive (at the domestic level against Guayaquil, at the international level against other maritime centres in the Pacific Ocean) and more profitable. An extension of the port activities and higher revenue from international tourism are seen as the only warrants of future development.

We have already said, in relation to Maranguape, that the economic rebirth of the 1990s, which affected all the municipalities of the Fortaleza municipal zone, is directly linked to international competition and the restructuring of the means of production imposed by trade globalisation. Since production costs are lower in the Nordeste than in the more industrialised south of Brazil, domestic companies and subsidiaries of foreign groups move to these hitherto disadvantaged regions in order to increase their profit margins on exports. As for Cuenca, international economic and financial flows are becoming a key factor of local and micro-regional development. The spending power of families in this equatorial region is to a large extent supported by expatriates, and it is this financial input that now defines the value of goods and their purchase price. Is this a recurring form of economic dependency, which characterises the relationship between countries of Southern or Eastern, and Western Europe, or Central America and the USA? Or should it be seen, like the "dollarisation" of its currency, as a part of the globalisation of Ecuador's economy? This growing openness towards the world, currently more the fruit of circumstance than choice, is both a problem for public authoritiesdue to its influence on the cost of living in the region-and an opportunity to cope with the economic crisis, thanks to a falling rate of unemployment and significant financial mobilisation. Estimates have it that almost US\$ 400 million are sent each year to Azuay y Cañar provinces by emigrants. To be used effectively, these require a rational local investment strategy.

To conclude, let us briefly reflect on the localglobal dialectic which seems to underpin the great lines of economic development as they appear in the four cities, and as they have been programmed 
for the years to come. The local level is that of the day-to-day, the basic, the indispensable. It is at this level that urban players and economic stakeholders - the work force, job seekers, migrants, employers, public administrators-get together to define, in more or less individual or concerted fashion, the paths they must follow to foster employment, boost income and economic profitability, and to improve the domestic position of cities and their regions. The international level is marked by market globalisation and the speeding up of trade; the relevant rules directly or indirectly influence domestic and local economies. As a corollary to economic globalisation, urban players, both public and private prove extremely receptive to exogenous opportunities, such as tourism in Manta or Cuenca in Ecuador. However, entering permanently unstable markets is not without its dangers. Competition is fierce; one must adapt rapidly to changes in the international markets, and supply high quality "products" to a very volatile market. These products include both manufactured goods and raw materials, but also the men and women who sell their labour under extremely precarious conditions. There is a tightening of production and sales prices and negative pressure on local revenue. Making choices in an unforeseeable international context is always risky. Nor should we forget, to quote Peemans (2002), that recent world developments clearly show that it is naive to believe that a country which pursues entry into the global market as its unique strategy will be able to maintain its level of social welfare and the standard of living of its resident population.

Between these two poles - the local and the global - the second, domestic level seems to disappear. In fact, not much mention is made of it in the studies of the four towns, nor is it significantly represented in the main development lines decided upon by the local partners during the research process. The rise of local urban players seems to go hand in hand with the disappearance of the historic, often vertical link, between national policies and local strategies. There can be no doubt that this illustrates the loss of power by the central state and a power gain by economic decision-makers, again an effect of economic globalisation. It also signals the rallying of local and micro-regional economies and identities that characterises true territorial decentralisation. We must be watchful, however. This apparent weakening of the link between the local and the national level of economic development and the relevant strategies may give rise to initiatives that are as creative and original as they are disparate and fragile - and in a violently competitive context.

\section{Multi-dimensional aspects: the other characteristics of "intermediation"}

What other aspects of "intermediation" that seemingly guide present and future action did we discover in the four cities, and what lessons are to be learned from them? In each of these cities, the main lines of the reflection on "intermediation" were chosen by those who promote this type of approach; an initial seminar defined these lines, as well as priority issues to be examined, and procedures to be established for follow-up. The lines reflect both the local players' perception of the process: emerging aspects, central research pathways, and actions to be undertaken in a context of voluntary-and sometimes involuntary-exchange.

The local teams pointed out four aspects which greatly interest them, and are bound to guide the decisions and projects they implement, thanks to more informed interaction with the outside world:

- The political-institutional aspect: this is readily explained by the fact that public authorities are a major partner in this research project, and control the planning and coordination of the main lines of development and investment.

- The aspect of services and equipment: these pragmatically back-up a number of choices in order to promote positive "intermediation" regulated by the city for its own benefit.

- Territorial and environmental aspects: these represent the physical space which formed the backdrop for negotiations between and interests of the various stakeholders.

- Last, we must mention two other dimensions which are very close in their approach to the issues at hand: the cultural and the social. Both illustrate how citizens take possession of the choices made by political or economic decisionmakers to imagine the future of their cities and their external relations.

Such local analyses are interesting on several counts. They were conducted by highly committed ad hoc teams, who seized this opportunity to cast a fresh eye on their own situation. These "observatories of urban complexity" with their mixed working groups may be the harbingers of future cooperation between public and private operators, civic and scientific organisations. The results they obtained, and the difficulties generated by the necessity to work in a preestablished comparative framework, make it clear that to be sustainable, this budding process will have to receive continued logistic and technical support.

The insistence on improved urban functioning and better living conditions highlighted four principal characteristics: The first is a focus on the city's 
"local affairs" to the detriment of areas that link the urban entity with its environment; the second favours future projections over the analysis of current reality; the third is marked by a positivist attitude which centres more on future initiatives to improve local life than on current constraints born of the intermediate city status - after all, it is easier to discuss economic plans than migratory pressure or environmental degradation. The fourth reveals the primacy of global dynamics, i.e. local players give priority status to projects that depend largely on external resources, such as tourism or industrial export.

\section{From understanding to action: urban "intermediation", an aid to local urban management}

The conceptual basis of this study and its application in four specific urban contexts enabled us to make a critical examination of the hypotheses which constitute the theoretical framework of research and monitoring. We stated that "intermediation" is a component of urban management, but should not simply be assimilated with it. In fact, it represents the totality of human and institutional activities that organise exchange between a specific entity, i.e. the city with its authorities and residents, and the outside world with its various horizons: local, micro-regional, national, global. The results of our study do not contradict this; it appears that the existing or planned relations established by the players in each town with their external partners are manifold, rich and varied, and that they usually involve projects for the city's and region's future development.

That said, we must first comment on how they themselves view this phenomenon. For many, the functional specificity of "intermediation" is abstract and difficult to grasp in terms of management and planning. Urban stakeholders will have to be educated and made aware of these issues, regardless of the sector they represent, so that they may understand not only the potential of "intermediation" (which is the aspect they most readily assimilate in terms of economic projects) but also its risks. In fact, risks are often ignored, whereas they should serve diagnostic purposes and help in the realistic planning of projects (e.g. environmental contamination and impact of urban immigration).

The second observation touches upon each city's demographic and spatial characteristics. After the study of these four cities, each of which represents a different urban type, we can say the following: although "intermediation" must be examined through the functions that the city fulfils, it is true that relevant initiatives will depend on each city's demographic and territorial clout. Certain func- tions depend directly on population size - a metropolis participates differently in the globalised urban fabric than a small provincial town. Others are independent of the city's capacities; for example, its role as a commercial platform for its hinterland, or as an administrative and political capital. The same may be said of the spatial dimension. The location and geographic characteristics of each city may become obstacles to its exogenous development, or opportunities - as is the case with border cities, tourist areas or communication centres.

The "intermediation" concept is applicable to a wide range of cities. From these, we can derive a typology based on the multi-dimensional character of this concept, and the importance of its interactions. Depending on the size of a city and the strategies introduced by its stakeholders, its spatial and socio-political position, certain aspects will take precedence over others-we have seen that economic aspects are always present, whereas demographic factors are often ignored. This applies to all territorial levels, i.e. the micro-regional for small rural towns, the regional and national for administrative capitals, the international for industrial or tourist centres.

It also became apparent that the rural-urban interface is a major element of some cities' intermediate role. Here, the multifunctional character of these agglomerations is most visible, particularly in the regional centres that provide an outlet for farmers' products and function as a public and private service centre for them. Keeping in mind that a large part of the population still lives in rural regions (even though this part is smaller in Latin America than on other continents), it is obvious that medium-sized intermediate cities are of capital importance in the transformation of their country, as regional exchange centres, as well as relays to the upper echelons of the administrative and political apparatus. In parallel to the traditional functions of regional urban centres, political decentralisation and consolidation strategies now offer them added opportunities to hold on to the rural populations that used to migrate directly to the large metropolitan centres and their peripheries. This phenomenon, observable for several decades in Europe, has now reached Latin America.

Other characteristics of intermediation have been determined by the local studies, and feed into our hypotheses. Medium-sized intermediate cities occupy a particular space within urban networks: we observe that local players who defend a common cause, whatever their socio-economic position or affiliation, take a common stand against external agents, notably the state and major domestic or international companies. This feeling of a common identity reinforces the urban community and helps define strategies for concerted action between local 
players. This goes for all four cities; their mediumsized spatial and demographic dimensions facilitate communication and contact, in both logistical and social terms, defining forms of urban governance that are easier to implement than in larger agglomerations.

We also observed that the choices relating to the future of the cities seem never to be discussed in ideological terms, creating the impression that we are dealing with public policies devoid of issues of power, without conflicts or antagonistic positions. This "peacefulness" in no way reflects the urban reality. Rather, it should be seen as a unifying message that is part of a promotional strategy directed towards the outside. We must remain attentive to the tensions and contradictions behind such unifying projects, and avoid the pitfalls of overly superficial analyses of the social movements that drive the large debates concerning the fundamental choices promoted by local players.

We stated repeatedly that globalisation brings new opportunities for intermediate cities, enabling them to compete more effectively with the large metropolitan centres and with government strategies. Maranguape, a peripheral city in the orbit of Fortaleza, the major city of the Nordeste, now hosts domestic and international companies who consider it better adapted to their logic of global expansion. Economic globalisation runs like a thread through all projects planned by local leaders. Nevertheless, the cities we studied still lack a clear idea of how to open up internationally, and have a tendency to systematically recuperate solutions that are fruitful only if adapted to a specific profile. For example, export and international tourism may be development strategies, or symbols of a "residual modernity".

The relative silence surrounding the problems and negative effects of "intermediation"-notably as concerns the environment-largely explains why, over and above internal management issues, the functioning of intermediate cities does not yet favour conflicts and power struggles. Foreseeably, the extension of globalisation and subtler urban expansion strategies will make contradictions between export trade and the preservation of natural resources, or between traditional social ties and migration, more apparent, and create areas of conflict that are not yet visible.

To conclude, we may say that the cities we studied, and by extension a number of urban agglomerations, have a double affiliation: their intermediate function on the one hand, their position of medium-sized town within the urban hierarchy on the other. Owing to their social and territorial specificities, intermediate cities are a privileged environment for regional planning linking urban growth and regional equilibrium in a positive dynamic between the urban and the rural. They supply goods and public and private services to the region's urban and rural populations. They often function as administrative centres, representing the provincial and national authorities. Moreover, they concentrate a number of secondary and tertiary activities that are indispensable to life within society (banks, retail and wholesale businesses, telecommunications, etc.). They are the heart of a region and regulate the flows that irrigate it, serving as mediators towards the higher echelons of the economic and administrative structure - the country, the world. Due to political and administrative decentralisation on the one hand, to the liberalisation of economic exchange on the other, these regional development factors will grow stronger in the years to come, reducing the role of the state in the regulation of goods, capitals and persons.

It is all the more disquieting that so few initiatives proposed by urban players participate directly in regional development strategies concerted with other public or private parties. Among the four cities we studied, Camilo Aldao may be the one in which the will to cooperate at regional level is the most manifest. This is because it is a small town and its future is linked directly to the economic and social prosperity of the region. The other cities, with economies of scale (a larger population allows for more autonomous urban management) view "the region" as part of their own urban project - the region backs their local strategy, as in the Manta metropolitan zone - instead of negotiating a regional strategy that intrinsically links the cumulative advantages of rural and urban regions within a global project. Obviously, these issues can be tackled only by concerted moves that go beyond the spatial and administrative limits of urban agglomerations. And it is by no means certain that the bitter competition that territorial collectivities of all kinds may engage in will provide the best stimulus for change in times to come. This makes it all the more necessary to reformulate the problem in political terms, to ensure that relevant decisions account for the advantages and problems that come with each of the planned solutions.

The options proposed by urban decision-makers in the case studies actually contributed few alternatives to the classic position of intermediate cities in the Third World, all too often guided by the apparent opportunities of an increasingly globalised economic market. Moreover, their position may be somewhat naive and may increase their dependency upon outside decision-makers. On the other hand, these cities show strong creativity in often hostile conditions (think only of the current economic situation of Ecuador or Argentina), and are more than willing to benefit from a more flexible regulatory framework. Obstacles are not much discussed. No mention is made of the weaknesses of the administrative organisation, nor of scarce financial, technical and human resources, political, 


\section{Intermediate cities in Latin America: J-C Bolay, A Rabinovich}

legal and financial dependency on provincial and national authorities, geographic isolation or territorial and political marginalisation. The impact of urbanisation on close or more distant regions in terms of the deterioration of natural resources, the settlement of agricultural land, or other damages, may in the longer run lead to serious tensions between partners in a regional development process that ought to be sustainable.

The "intermediate city" should be viewed as a polymorphous conceptual construction, one which is still growing. Ultimately, its role will depend on our capacity to show the players concerned that it may serve as a tool for improved management, both owing to the critical stance it takes towards the surrounding world, and by rendering decisionmaking more objective by introducing different dimensions of analysis at various levels of interaction. The possible contradictions between internal contingencies, linked to the "life of the city", and external explorations - whether desired, experimented or imposed - generate a renewed vision of the urban phenomenon; both as a system (all decisions, be they local and isolated, or global and concerted, will have an impact on the future of the city and of its relations with its natural social and economic environment). It may also be seen as a dynamic system, since standpoints and resulting decisions are fine-tuned in the course of the debates they generate and may help understand social, political and economic conflicts in the urban world. In this sense, if intermediate cities are more rigorously studied and thus better understood, they will be able to reveal changes that go well beyond urban planning and development issues (important as these may be). Tracked by means of social participation processes - in our case, the local observatories - intermediate cities will serve as very effective urban governance laboratories, dealing with fundamental problems, seeking to integrate individual citizens and social groups within an urban environment less marked by competition and domination than by a respect for rights and the complementary functions of urban and rural communities, of agglomerations of different size and character, of cities and regions cast into a globalised world they hope to benefit from although they are often sadly misinformed of the principles that govern international economic domination and exploitation.

\section{References}

Ascher, F (2000) Ces événements nous dépassent, feignons d'en être les organisateurs. Essai sur la société contemporaine. l'Aube Essai, Paris.

Ascher, F (1995) Métapolis ou l'avenir des villes. Odile Jacob, Paris.

Ayuntamiento de Lleida, UNESCO, UIA (ed.) (1999) Ciudades intermedias y urbanización mundial. Municipalidad de Lleida, Lleida.
Bolay, J-C, Cabannes, Y, Carrion, A and Rabinovich, A (2002) Intermediación urbana: ciudades de América Latina en su entorno. Cuaderno de trabajo 100, PGU/ALC, Quito.

Bolay, J-C (1995) Métropoles du tiers monde: quel environnement pour demain? In Métropolisations: interdépendances mondiales et implications lémaniques. (eds.) M Bassand, D Joye and J-P Leresche, Georg, Genève.

Colin Delavaud, A (1994) IHEAL. In Problèmes d'Amérique, no. 14.

Devas, C N (1999) Who runs cities? Working Paper 4, Urban Governance, Partnerships and Poverty Research, IDD, University of Birmingham, Birmingham.

Galileo, S (1994) Modelo de gestión para ciudades intermedias en America Latina. CEPAL/CNUAH and Gobierno de los Países Bajos.

GRAL/CEDAL (1994) Villes intermédiaires vitalité économique et acteurs sociaux. In Problèmes d'Amérique Latine, no. 14, La documentation française, juillet-septembre, Paris.

Hall, P and Pfeiffer, U (2000) Urban Future 21. E\&FN Spon, London.

Hardoy, J E, Mitlin, D and Satterthwaite, D (2001) The rural, regional and global impacts of cities in Africa, Asia, and Latin America. In The Earthscan Reader in Sustainable Cities. In The Earthscan Reader in Sustainable Cities. (eds.) D Satterthwaite, Earthscan Publications Ltd, London.

Hardoy, J E, Satterthwaite, D, 1989. Small and Intermediate Centres, their Role in National and Regional Development in the Third World. Hodder and Stoughton, London.

Healey, J and Robinson, M (1992) Democracy, Governance and Economic Policy. Overseas Development Institute, London.

Marcuse, P and Van Kempen, R (2000) Globalizing Cities, A New Spatial Order? Blackwell Publisher, Oxford.

Merrien, F X (1997) De la gouvernance comme évolution convergente à la gouvernance comme arrangements contingents. In Gouvernance métropolitaine et transfrontalière, action publique territoriale. (eds.) G Saez, J-P Leresche and M Bassand, L'Harmattan, Paris.

Paquot, T (1996) Le monde des villes, panorama urbain de la planète. Complexes, Paris.

Pedrazzini, Y (1995) Créolité et chaos de la métropole latinoaméricaine. In Métropolisations: interdépendances mondiales et implications lémaniques. (eds.) J-Ph Leresche, D Joye and M Bassand, Georg, Genève.

Peemans, J-P (2002) L'Etat entre les exigencies des acteurs globalistes et les demandes populaires de développement: aspects Nord et Sud. Université Nationale de Colombie, Bogota.

Peemans, J-P (2003) Le développement des peuples face à la mondialisation $d u$ monde. Les théories du développement face aux histoires du développement «réel» dans la secodemoitié du Xxème siècle. In Population et Développement, vol. 10, Academia Bruylant and L'Harmattan, Louvain la NeuveParis.

Petrella, R (1996) Is it possible to promote "intermediary" cities sustainability within the present context of triumphant global market competitive capitalism. In Intermediate Cities in Search of Sustainability, European Foundation for the Improvement of Living and Working Conditions. (eds.) J-Ph Leresche, D Joye and $\mathrm{M}$ Bassand, Loughlingstown, Shankill, Co, Dublin.

Pugh, C (2000) Sustainable cities in developing countries. Earthscan Publications Ltd, London.

Rakodi, C (1999) Urban Governance, Partnership and Poverty: A Preliminary Exploration of the Research Issues. University of Birmingham, Urban Governance, Partnership and Poverty Working Paper 8, Birmingham.

Rossi, M, (1999) Décentralisation et Développement. DDC, Berne.

Stren, R (2002) New approaches to urban governance in Latin America. CIID Conference, Montevideo 6-7 April 2000, Available from http://www.idrc.ca/lacro/docs/conferencias/ stren.html.

Tacoli, C (1998) Rural-urban interactions: a guide to the literature. In Environment and Urbanization, vol. 10, no. 1, IIED, London. 
Intermediate cities in Latin America: $J$-C Bolay, A Rabinovich

UN (2002) World Urbanization Prospects. The 2001 Revision. ST/ ESA/SER:A/216, United Nations Population Division, New York.

UNCHS HABITAT (1996) An urbanizing world: global report on human settlements 1996. Oxford University Press, London.

UNCHS HABITAT (2001) Cities in a Globalizing World. Global Report on Human Settlements. Earthscan Publications Ltd, London.
UNCHS HABITAT (2003) The global campaign on urban governance, UNCHS, Nairobi, Available from http://www.unchs.org/campaigns/governance/principles.asp.

UNESCAP (2003) What is good governance. Human Settlements, United Nations Economic and Social Commission for Asia and the Pacific, Available from http://www.unescap.org/ huset/gg/governance.htm. 